\title{
Özefagus Atrezisi: Tek Cerrah, Tek Merkez Deneyimi ve Sonuçları
}

\author{
Mustafa 0kumuş@i)
}

Yeni Yüzyıl Üniversitesi Tıp Fakültesi, Çocuk Cerrahisi Anabilim Dalı, İstanbul, Türkiye

Mustafa Okumuş, Dr. Öğr. Üyesi

İletişim:

Dr. Öğr. Üyesi Mustafa Okumuş

Yeni Yüzyıl Üniversitesi Tıp Fakültesi,

Çocuk Cerrahisi Anabilim Dalı, İstanbul, Türkiye

Tel: +902126153838

E-Posta:drmustafaokumus@gmail.com
ÖZET

Amaç: Çocuk cerrahisi kliniklerinin indeks vakalarından biri olan özefagus atrezisi halen ayrı bir öneme sahiptir. Başarılı sonuçlar için multidisipliner yaklaşım, donanımlı bir klinik ve cerrahi tecrübe gerekir. Sıklıkla büyük eğitim hastanelerinde tedavileri yapılsa da, donanımlı özel hastanelerde de başarılı sonuçlar alınabileceğini göstermek istedik.

Materyal ve Metot: Geriye dönük gözlem olarak planlanan çalışma için, 2007 ve 2017 yılları arasında kliniğimizde özefagus atrezisi tanısı konulmuş ve tedavisi yapılmış, hastalar çalışmaya dahil edildi.

Sonuçlar: Toplam 29 hasta çalışmaya dahil edildi. 29 hastanın 28 'sinde primer anastomoz yapılabildi. Ortalama takip süresi 48,5 ay olarak bulundu. Tüm grupta sağkalım oranı $\% 89,6$ olarak saptandı. Anastomoz kaçağı olan hastaların oranı $\% 17,8$ olarak bulunurken, anastomoz darlığı hastaların $\% 50$ 'sinde saptandı. Çalışmaya dahil edilen 29 yenidoğanın 17 'si erkek $(\% 58,6)$ ve 12 'si kızdı $(\% 41,4)$. Ortalama gestasyonel yaş 36,2 $\pm 2,4$ olarak saptanırken, ortalama ağırlık $2470 \pm 687$ gram olarak bulundu. Çok düşük doğum ağırlğı (<1500 gr.) olan 4 hasta mevcuttu. Kardiyak anomali 15 hastada $(\% 51,7)$ saptanırken, VACTERL sendromu 4 hastada saptandı.

Tartışma: Multidisipliner çalışma sayesinde özefagus atrezisinin tanı ve tedavisinde büyük gelişmeler sağlanmaktadır. Önceden büyük eğitim hastanelerinde tedavileri yapılabiliyor olsa da, günümüzde yeterli alt yapısı olan diğer hastanelerde de başarılya tedavi edilebileceğini düşünmekteyiz.

Anahtar sözcükler: Özefagus atrezisi, Trakeoözefajiyal Fistül

\section{ESOPHAGEAL ATRESIA: SINGLE SURGEON, SINGLE CENTER EXPERIENCE AND RESULTS}

\section{ABSTRACT}

Objective: Esophageal atresia, one of the index cases of pediatric surgery clinics, is still of particular importance. A multidisciplinary approach, a well-equipped clinic and surgical experience are required for successful results. Although it is often done in large training hospitals, we aimed to show that satisfactory results can be obtained in any specialized hospital.

Material and Method: Medical records of infants with repaired esophageal atresia from 2007 to 2017 were reviewed.

Results: A total of 29 patients were included in the study. The primary anastomosis was performed in 28 of 29 patients. The median follow-up was 48.5 months. The overall survival rate was $89.6 \%$. Incidence of anastomotic leakage was $17.8 \%$, anastomotic stricture $50 \%$ (33.3\% within the first year). Recurrent fistula and vocal cord paresis were not revealed. Trans-anastomotic stent and chest drain were routinely used. The mean gestational age was found to be $36.2 \pm 2.4$ and the mean weight was $2470 \pm 687 \mathrm{grams}$. There were 4 patients with very low birth weight $(<1500 \mathrm{~g})$. The cardiac anomaly was detected in 15 patients (51.7\%) and VACTERL syndrome was detected in 4 patients.

Conclusions: Great advances in diagnosis and treatment are provided related to the multidisciplinary approach. Although the treatment of esophageal atresia could be performed in large training hospitals up to date, we think that it can be successfully treated in other hospitals with adequate infrastructure.

Keywords: Esophageal atresia, Tracheoesophageal fistula 
zefagus atrezisi (ÖA), yaklaşık 3500 canlı doğumda bir görülen, nadir bir konjenital anomali olsa da, kompleks yapısı, morbidite ve mortalitesi nedeniyle çocuk cerrahisi kliniklerinde önemini halen korumaktadır (1). Cameron Haight'in 1941 deki ilk başarılı ameliyatından sonra, anestezi, yoğun bakım ve cerrahi tekniklerdeki ilerlemeye paralel olarak, sağ kalım oranları giderek artmış olmakla birlikte morbiditede önemli değişiklikler olmamıştır (2). Bütün yönleriyle ÖA tedavisi birçok kliniğin ortak çalışmasını gerektirir. Daha çok eğitim kliniklerinde tedavisi ve takibi yapılan ÖA vakalarının artık yeterli donanımı olan diğer merkezlerde de başarılı bir şekilde tedavi edilebileceğini biliyoruz. Bu amaçla son on yılda kliniğimizde tedavisini ve takibini yaptığımız hastalarımızın sonuçlarını paylaşmayı amaçladık.

\section{Materyal ve metot}

Geriye dönük gözlem olarak planlanan çalışma için, hasta dosyaları incelendi. 2007 ve 2017 yılları arasında kliniğimizde özefagus atrezisi tanısı konulmuş ve tedavisi yapılmış, hastalar çalışmaya dahil edildi. Hastaların demografik özellikleri, tanı ve tedavi yöntemleri, ameliyat sonrası seyir ve komplikasyonlar, morbidite ve mortalite değerlendirildi.

\section{Ameliyat öncesi değerlendirme}

Her hasta üst poş grafisi ile değerlendirildi. Ameliyat öncesi her hastaya antibiyotik tedavisi başlandı ve düzenli üst poş aspirasyonu yapıldı. Tüm batın ultrasonografisi ve ekokardiyografi rutin olarak her hastaya yapılırken ameliyat öncesi bronkoskopi rutin olarak kullanılmadı.

\section{Cerrahi teknik}

Tüm hastalarda açık cerrahi teknik kullanıldı. Klasik sağ posterolateral kas koruyucu torakotomi yapıldı (ekstraplevral yaklaşım). Vena azigos bağlanıp kesildikten sonra alt poş diseke edilerek fistül divizyonu ve takiben üst poşun diseksiyonu yapıldı. Trans-anastomotik $6 \mathrm{~F}$ beslenme tüpü ve $12 \mathrm{~F}$ göğüs tüpü tüm hastalarda rutin olarak kullanıldı. Tüm ameliyatlar aynı çocuk cerrahisi uzmanı tarafından gerçekleştirildi.

\section{Ameliyat sonrası takip}

Tüm hastalar operasyon sonrası entübe olarak yenidoğan yoğunbakım ünitesine alındı ve en az bir gün süreyle mekanik ventilasyon desteğinde takip edildi. Özefagus pasaj grafisi 5. veya 6. gün çekilirken, hasta beslenmeye başladıktan bir gün sonra göğüs tüpü çekildi. Anastomoz kaçağı olan durumlarda göğüs tüpünün çekilmesi için kaçağın kapanması beklendi. Dilatasyon gerektiren semptomatik darlıklar için rijit ve balon dilatatörler kullanıldı.

\section{Sonuçlar}

Çalışma süresi içinde kliniğimizde tedavisi ve takibi yapıIan 29 hasta çalışmaya dahil edildi. Ortalama takip süresi 48,5 ay (4 yıl) olarak hesaplandı. Gross sınıflandırmasına göre tip A ve E grubunda birer hasta varken $(\% 3,4)$ tip C grubunda $27(\% 93,1)$ hasta vardı. Prenatal tanısı konulmuş hasta olmamakla birlikte hastaların sadece üçünde prenatal dönemde polihidroamnios saptanmıştı $(\% 10,34)$.

Çalışmaya dahil edilen 29 yenidoğanın 17'si erkek $(\% 58,6)$ ve 12 'si kızdı $(\% 41,4)$. Ortalama gestasyonel yaş $36,2 \pm 2,4$ hafta ve ortalama ağırlık $2470 \pm 687$ gram olarak bulundu. Çok düşük doğum ağırlığı (<1500 gr.) olan 4 hasta mevcuttu. Kardiyak anomaliler en sık rastlanan ek anomalilerdi (n: 15). Diğer ek anomalilerin dağılımı tablo 1'de gösterilmiştir.

$\begin{array}{lcc}\text { Tablo 1. Ek anomalilerin dağılımı } & & \\ \text { Kardiyak anomali } & 15 & \% 51,7 \\ \text { Anal atrezi } & 6 & \% 20,6 \\ \text { İnmemiş testis } & 3 & \% 10,3 \\ \text { Üretra anomalisi } & 3 & \% 10,3 \\ \text { Hidrosefali } & 3 & \% 10,3 \\ \text { Renal agenezi } & 2 & \% 6,8 \\ \text { Vertebral Füzyon } & 2 & \% 6,8 \\ \text { Extremite anomalisi } & 2 & \% 6,8 \\ \text { Duodenal atrezi } & 1 & \% 3,4 \\ \text { VACTERL (üç veya daha fazla) } & 4 & \% 13,7\end{array}$

İki preterm hastada respiratuvar distres sendromu nedeniyle ameliyat öncesi dönemde mekanik ventilasyon ihtiyacı oldu. Bu hastalarda entübasyon sonrası batın distansiyonu ve mide perforasyonu gelişti. Genel durumları ve periferik dolaşımları bozulan hastalara ilk önce basit periton dreni ile müdahale edildi. Gerekli cerrahi müdahaleler 12-24 saat sonra genel durumları düzeldiğinde yapıldı. İki hastaya da önce torakotomi ve aynı seansta laparatomi yapıldı. Özefagus anastomozu ve primer mide perforasyonu onarımı yapılan hastalardan ilkine 45. gün hidrosefali için ventriküloperitoneal şant takıldı ve ameliyat sonrası 55. gün diğeri ise 17 gün şifa ile taburcu edildi.

Hastaların 28'inde primer anastomoz yapılabildi. İzole özefagus atrezisi saptanan bir hastada, üst poş çok uzun olmasına rağmen alt poş güdük şeklinde olduğu için özefagostomi ve gastrostomi yapıldı. Bir diğer hastada ise aradaki mesafe uzun olduğu için üst poş flebi kullanıldı ancak takibinde anastomoz tam olarak ayrıldığı için 
gastrostomi ve özefagostomiye dönüldü. Bu hastaların ilkinde, anal atrezi ile ilgili ameliyatları sonuçlandırıldıktan sonra, yaklaşık 4 yaş civarında, başka bir merkezde mide tüpü ile özefagus devamlılığı sağlandı. Diğer hasta ise 9 . aydan sonra takibimizden çıktı. Operasyon sonrası rutin olarak, tüm hastalar mekanik ventilasyon desteğinde takip edildi. Mekanik ventilasyon desteğinde takip edilen süre 1 ila 8 gün arasında değişirken ortalama $3,8 \pm 1,6$ gün olarak saptandı.

Primer anastomoz yapılan 28 hastanın beşinde $(\% 17,8)$ anastomoz kaçağı oldu. Bu hastalardan birinde anastomoz tamamen ayrıldığı için özefagostomi yapılmıştı. Diğer dört hastada ise kaçaklar postoperatif 10., 11., 13. ve 14. günlerde kesildi. Anastomoz kaçakları tamamen düzelene kadar, toraks tüpleri yerinde bırakıldı. Hastanede kalış süresi, taburcu edilebilen hastalar için ortalama $21,1 \pm 12,7$ gün olarak hesaplandı.

Illk yıl içinde $8(\% 33,3)$ hastada semptomatik özefagus darlığı saptanırken, toplamda 12 (\%50) hastada dilatasyon gerektiren darlık saptandı (primer anastomoz yapılan ve yaşayan hastalar arasında N: 24). Bu hastalara toplamda 21 kez dilatasyon yapıldı. Illk altı ay içinde rijit bujiler (Hegar) ile dilatasyon yapılırken, daha büyük hastalarda balon dilatatörler kullanıldı. Tüm dilatasyonlar genel anestezi altında yapıldı. Bir hastada 4, iki hastada 3, iki hastada 2, yedi hastada 1 kez dilatasyon yapıldı (ortalama 1,6 dilatasyon). Tüm hastalarda en az üç ay süreyle $\mathrm{H}_{2}$ reseptör blokörleri kullanılırken semptomatik darlık saptananlarda bu süre bir yıla kadar uzatıldı. Antireflü cerrahisi hiçbir hastada gerekmedi. Tekrar eden fistül ve laringeus rekurrens siniri hasarına bağlı vokal kord paralizisi takip süresi içinde tespit edilmedi. İi hastada trakeomalazi saptansa da takiplerinde, cerrahi tedaviye gerek kalmadan düzeldiği gözlendi.

Tüm grupta sağ kalım oranı $\% 89,6$ olarak bulundu. Kaybedilen 3 hastanın birinde Büyük arter transpozisyonu mevcuttu ve patent duktus arteriyosusa bağımlıydı. Solunum sıkıntısı olan ve mekanik ventilasyon desteğinde olan, batın distansiyonu da gelişmeye başlayan hastaya pediatrik kardiyoloji ve pediatrik kardiyo-vasküler cerrahinin de kararı ile prostavazin desteği altında primer anastomoz yapıldı. İkinci gün renal yetmezlik gelişen ve periton diyalizi yapılan hasta 3. gün kaybedildi. Diğer iki hastanın birinde ağır asfiksi diğerinde ise intrakraniyal kanama mevcuttu. Her iki hasta da özefagusla ilgili problemleri yokken 42. ve 60. günlerde kaybedildi. Spitz sınıflandırmasına göre mortalite oranları tablo 2'de gösterilmiştir.

\begin{tabular}{|c|c|c|c|}
\hline Gruplar & $\begin{array}{c}\text { Tüm } \\
\text { yenidoğanlar } \\
N=29\end{array}$ & $\begin{array}{c}\text { Exitus } \\
N=3\end{array}$ & $\begin{array}{c}\text { Sağkalım oranı } \\
\% 89,6\end{array}$ \\
\hline $\begin{array}{l}\text { I. >1500 gr. } \\
\text { Major kardiyak anomali yok }\end{array}$ & 22 & 1 & $\% 95,4$ \\
\hline $\begin{array}{l}\text { Il. }<1500 \text { gr. } \\
\text { Veya majör kardiyak anomali }\end{array}$ & 7 & 2 & $\% 71,4$ \\
\hline $\begin{array}{l}\text { III. <1500 gr. } \\
\text { Ve majör kardiyak anomali }\end{array}$ & $\emptyset$ & $\emptyset$ & $\emptyset$ \\
\hline
\end{tabular}

\section{Tartışma}

ÖA özel haller dışında acil cerrahi gerektiren bir hastalık değildir. Hastanın bütün yönleriyle değerlendirilip, en uygun şartlarda ameliyata alınmasının mortalite ve morbidite üzerinde önemli etkisi vardır (3). Genellikle birçok ek anomalinin birlikteliği söz konusu olsa da prognozu en çok etkileyen kardiyak anomalilerdir. Normal kardiyak muayenenin yeterli olduğunu söyleyen yazarlar olsa da bu gün birçok merkezde ekokardiyografi rutin olarak yapılmaktadır (4). Ameliyat öncesi yapılan bronkoskopi fistülün yerini tam olarak tespit etmemize ve proksimal fistülün varlığını ortaya koymamıza yardımcı olmasına rağmen halen yaygın kabul görmemektedir $(2,4)$. ÖA cerrahisinde, kesin enfeksiyon bulguları yok ise antibiyotik kullanımının sonuçlar üzerine önemli bir etkisi yoktur $(4,5)$. Ameliyat sonrası dönemde ise neredeyse vakaların \%90'nın da kas gevşetici ilaç tedavisi ve mekanik ventilasyon kullanılmaktadır (4).

ÖA ameliyatlarında amaç hastanın doğal özefagusunu korumak ve özefagus bütünlüğünü sağlamaktır. Bu amacımızı birçok hastada gerçekleştirebiliyor olsak da aradaki mesafenin fazla olduğu hastalar önemli bir sorun oluşturur. Bu hastalarda doğal özefagusu korumak için çeşitli alternatif yöntemler kullanılmaktadır. Geciktirilmiş primer onarım ve Foker yöntemi hemen hemen sonuçları aynı olan ve diğerlerinin arasında öne çıkan iki başarılı yöntemdir $(6,7)$. Bu yöntemlerle sonuç alınamazsa mide ve barsak kondüitleri kullanılabilir ama anastomoz kaçaklarının, darlıkların, motilite bozukluklarının, solunum sistemi semptomlarının ve ileri yaşlarda metaplazi ve kanser riskinin çok daha yüksek olduğunu da akılda tutmak gerekir (8-11). Primer anastomoz yapılamayan iki hastamızın sadece birinin uzun dönem takibini yapabildik. Bu hastada özefagus bütünlüğü büyük kurvaturdan hazırlanan mide tüpü ile sağlandı.

Minimal invazif yöntemlerin her geçen gün daha fazla kullanıldığı günümüzde, öğrenme süresi uzun olsa da 
torakoskopik özefagus atrezisi onarımı da giderek daha fazla yapılmaktadır. Sonuçlar karşılaştıııldığında iki teknik arasında anlamlı bir fark olmadığı görülmektedir (12-14). Buna rağmen özefagus atrezisi tedavisinde torakoskopik yöntemi kullanan çocuk cerrahisi uzmanlarının oranı halen \%10 un üzerine çıkmamıştır $(2,15)$.

Mortalite oranları bütün dünyada düşerken morbidite oranlarında ise anlamlı bir değişiklik yoktur (16). Bu nedenle günümüzde çocuk cerrahları, morbidite ile çok daha fazla uğraşır hale gelmiştir. Özefagus darlıkları, rekürren trakeoözefagial fistül, anastomoz kaçakları ve vokal kord paralizileri bunların önemli bir kısmını oluşturur. En önemli nedeninin gergin anastomozlar olduğu bilinen anastomoz kaçakları, vakaların ortalama \%20'sinde görülür $(6,15,16)$. Bu seride 5 hastada $(\% 17,8)$ anastomoz kaçağı gelişti. Anastomozun tamamen ayrıldığı hasta hariç tümü takiple düzelirken, bu sonuçlar güncel literatür ile uyumlu olarak değerlendirildi. İki özefagus poşu arasındaki mesafenin uzun olduğu ve anastomoz kaçağı gelişen hastalarda meydana gelen rekürren trakeoözefagial fistüller vakaların \%3-15'inde görülür $(1,2,6,16)$. Rekürren laringeal sinir hasarına bağlı gelişen vokal kord paralizisi görülme sıklığı ise \%6-\%20 arasında değişir ve en önemli nedeni üst poşun aşırı diseksiyonudur $(6,15,16)$. Bu seride takip süresince rekürren trakeoözefagial fistül ve vokal kord paralizisi saptanmadı.

Post operatif takip süreleri uzadıkça anastomoz darlıklarının görülme oranı artar ve literatüre göre bazı serilerde $\% 75$ 'lere kadar çıktığı görülür (2). Anastomoz gerginliği ve dolayısıyla anastomoz uçlarında gelişen beslenme bozukluğu önemli bir sebep olarak görülse de vaka sayısının hayli fazla olduğu iki çalışmada, trans-anastomotik tüplerin en önemli darlık sebebi olduğu belirtilmiştir $(1,13,15)$. Bu seride ameliyat sonrası ilk yıl içinde 8 (\%33) hastada özefagus darlığı saptandı ve takip süresi uzadığında hasta sayısının 12'ye (\%50) yükseldiği görüldü. Tedavinin ilk basamağını dilatasyonlar oluştururken anti-asit tedaviye bir yıl süreyle devam edildi. Tüm hastalarda tedaviye yanıt alındığı için farklı bir tedavi yöntemine gerek olmadı.

Ameliyat sonrası gelişen özefagus darlıklarının tedavisinde, rijit bujilerle veya balonla yapılan dilatasyonlar oldukça başarılıdır (17). Dirençli darlıklarda sonuçları çok net olmasa da intralezyonel streoid ve mitomisin kullanılabilir (17). Özefagus stentleri bir alternatif tedavi şekli olabilir ve hatta antifibrinolitik kaplı stentlerin tedavide umut vadettiği söylenebilir (18). Kısa ve dirençli darlıklarda cerrahi rezeksiyonun her zaman tercih edilebilecek güvenli ve etkili bir yöntem olduğunu da unutmamak gerekir (19).

Gastroözefajiyal reflü hastaların yaklaşık \%27-72 sinde görülür ve anastomoz darlığı gelişiminde de etkisi olduğu gösterilmiştir $(20,21)$. Asit süpresyonu uygulanan ve uygulanmayan hastalar arasında anastomoz darlığı gelişimi açısından fark olmadığını söyleyen yazarlar olsa da cerrahların \%74'ü ameliyat sonrası standart olarak proton pompa inhibitörü veya $H_{2}$ reseptör blokörü kullanır $(15,20,21)$. Tedavide erken fundoplikasyonları öneren yazarların yanında yoğun medikal tedaviyi önerenler de vardır (2). Infantlarda anti-reflü ameliyatı sonrası nükslerin yaklaşık $\% 40$ 'larda olması bir yana, özefajiyal dismotilitenin zaten sorun olduğu bu hastalarda, fundoplikasyonun sorunu daha da artırabileceği unutulmamalıdır $(1,21)$. Cerrahi tedavinin, anti-reflü tedavisine cevap vermeyen, aspirasyon belirtileri ve apneik atakları olan hastalar için daha doğru olacağını düşünüyoruz. Kliniğimizde cerrahi sonrası rutin $\mathrm{H}_{2}$ reseptör blokörleri kullanılırken, hiç bir hastaya anti-reflü cerrahisi yapılmadı.

Düşük doğum ağılıklı preterm bebeklerde ventilatör ihtiyacı olabilir. Bu durumda distal fistülden geçen havanın gastrointestinal sistemde distansiyona ve hatta mide perforasyonuna neden olabileceğini akılda tutmak gerekir. Entübasyon tüpünün ucunu fistülden daha ileriye yerleştirmek ilk akla gelen basit çözüm olsa da; acil gastrostomi, fistül oklüzyonu, peritoneal drenaj, hatta acil torakotomi ve fistül divizyonu gerekebilir $(4,21,22)$. Genel durumu bozulmuş bu hastalarda majör cerrahi girişim durumu daha da zorlaştırabilir. Bu nedenle iki hastaya ilk anda, basit peritoneal dren ile müdahale edilirken, 12-24 saat sonra aynı seansta önce torakotomi ve daha sonra laparatomi ile primer onarım yapıldı.

Hastanedeki ölümlerin en önemli üç sebebi, düşük doğum ağırlığı (1500 gram altı), ilk 24 saatte yapılan operasyonlar ve gestasyonel yaşın 28 haftadan küçük olmasıdır $(23,24)$. Bu seride Spitz 1. Grubuna girenlerde mortalite $\% 4,6$, 2. Grupta \%28,6 olarak bulundu. Bu sonuçlar literatür ile uyumlu olarak değerlendirildi.

ÖA hala çocuk cerrahisi kliniklerinin önemli indeks vakalarından biri olmaya devam ediyor. Multidisipliner çalışma sayesinde tanı ve tedavisinde büyük gelişmeler sağlanmaktadır. Önceden büyük eğitim hastanelerinde tedavileri yapılabiliyor olsa da, günümüzde yeterli alt yapısı olan diğer hastanelerde de başarılyla tedavi edilebileceğini düşünmekteyiz. 


\section{Kaynaklar}

1. Mortell AE, Azizkhan RG. Esophageal atresia repair with thoracotomy: the Cincinnati contemporary experience. Semin Pediatr Surg 2009;18:12-19. [CrossRef]

2. Donoso F, Kassa A-M, Gustafson E, Meurling S, Lilja HE. Outcome and management in infants with esophageal atresia - A single centre observational study. J Pediatr Surg 2016;51:1421-25. [CrossRef]

3. Sayari AJ, Tashiro J, Wang B, Perez EA, Lasko DS, Sola JE. Weekday vs. weekend repair of esophageal atresia and tracheoesophageal fistula. J Pediatr Surg 2016;51:739-742. [CrossRef]

4. Hunt RW, Perkins EA, King S. Peri-operative management of neonates with esophageal atresia and tracheo-esophageal fistula. Paediatr Respir Rev 2016;19:3-9. [CrossRef]

5. Warris A. Prophylactic antibiotics should be used in children with repaired oesphageal atresia and tracheo-oesophageal fistula: The case against. Paediatr Respir Rev 2015;18:62-63. [CrossRef]

6. Teague WJ, Karpelowsky J. Surgical Management of oesophageal atresia. Paediatr Respir Rev 2016;19:10-15. [CrossRef]

7. Conforti A, Morini F, Bagolan P. Difficult esophageal atresia: Trick and treat. Semin Pediatr Surg 2014;23:261-69. [CrossRef]

8. Dingeman C, Meyer A, Kircher G, Boemers TM, Vaske B, Till H, Ure BM. Long-term health-related quality of life after complex/or complicated esophageal atresia in adults and children registered in a German patient support group. J Pediatr Surg 2014;49:631-8. [CrossRef]

9. Gupta DK, Sharma S, Arora MK, Agarwal G, Gupta M, Grover VP. Esophageal replacement in the Neonatal period in infants with esophageal atresia and tracheoesophageal fistula. J Pediatr Surg 2007;42:1471-7. [CrossRef]

10. Gallo G, Zwaveling S, Van der Zee DC, Bax KN, de Langen ZJ, Hulscher JBF. A two-center comparative study of gastric pull-up and jejunal interposition for long gap esophageal atresia. J Pediatr Surg 2015;50;535-9. [CrossRef]

11. Kunisaki SM, Coran AG. Esophageal replacement. Semin Pediatr Surg 2017:26:105-15. [CrossRef]

12. Shanghoon L, Lee SK, Seo JM. Thoracoscopic repair of esophageal atresia with tracheoesophageal fistula: Overcoming the learning curve. J Pediatr Surg 2014;49:1570-72. [CrossRef]
13. Fusco JC, Calisto JL, Gaines BA, Malek MM. A large single-institution review of tracheoesophageal fistula with evaluation of the use of transanastomotic feeding tubes. J Pediatr Surg 2018;53:118-20. [CrossRef]

14. van der ZEEDC, Tytgat SHA, van Herwaarden MYA. Esophageal atresia and tracheoesophageal fistula. Semin Pediatr Surg 2017;26:67-71. [CrossRef]

15. Lal DR, Gadepalli SK, Downard CD, Ostlie DJ, Minneci PC, Swedler $\mathrm{RM}$, et al. Challenging surgical dogma in the management of proximal esophageal atresia with distal tracheoesophageal fistula: Outcomes from the Midwest Pediatric Surgery Consortium. J Pediatr Surg 2018;53:1267-72. [CrossRef]

16. Lal DR, Gadepalli SK, Downard CD, Ostlie DJ, Minneci PC, Swedler $\mathrm{RM}$, et al. Perioperative management and outcomes of esophageal atresia and traheoesophageal fistula. J Pediatr Surg 2017;52:124551. [CrossRef]

17. Manfredi AM. Endoscopic management of anastomotic esophageal strictures secondary to oesophageal atresia. Gastrointest Endoscopy Clin N Am 2016;26:201-19. [CrossRef]

18. Srinivasan N, Kozarek RA. The future of esophageal endoprosthetics including the use of biodegredable materials. Tech Gastrointest Endoscopy 2014;16:92-98. [CrossRef]

19. Zhu H, Shen C, Xiao X, Dong K, Zheng S. Reoperation for anastomotic complications of esophageal atresia and tracheoesophageal fistula. J Pediatr Surg 2015;50:2012-5. [CrossRef]

20. Shawyer AC, Pemberton J, Flageole H. Post-operative management of esophageal atresia-tracheoesophageal fistula and gastroesophageal reflux: A Canadian Association of Pediatric Surgeons annual meeting survey. J Pediatr Surg 2014;49;716-19. [CrossRef]

21. Robb A, Lander A. Oesephageal atresia and tracheo-oesophageal fistula. Surgery (Oxford) 2007;25:283-6. [CrossRef]

22. Spitz L. Esophageal atresia: past, present, and future. J Pediatr Surg 1996;3:19-25. [CrossRef]

23. Wang B, Tashiro J, Allan BJ, Sola JE, Parikh PP, Hogan AR, et al. A nationwide analysis of clinical outcomes among newborns with esophageal atresia and tracheoesophageal fistulas in the United States. J Surg Res 2014;90:604-12. [CrossRef]

24. Pini Prato A, Carlucci M, Bagolan P, Gamba PG, Bernardi M, Leva E, et al. A cross-sectional nationwide survey on esophageal atresia and tracheoesophageal fistula. J Pediatr Surg 2015;50:1441-56. [CrossRef] 